\title{
A proposal for enhancement of research capacities in Croatian general practice
}

\author{
Davorka Vrdoljak, Dragomir Petric
}

Department of Family Medicine University of Split School of Medicine Split, Croatia

\author{
Corresponding author: \\ Davorka Vrdoljak \\ Department of Family Medicine \\ University of Split School of Medicine \\ Šoltanska 2 \\ 21000 Split, Croatia \\ davorka.vrdoljak@mefst.hr \\ Tel.: + 38521568696 \\ Fax.: + 38521568696
}

Received: 26 March 2013

Accepted: 23 April 2013

Copyright (C) 2013 by

Academy of Sciences and Arts

of Bosnia and Herzegovina.

E-mail for permission to publish:

amabih@anubih.ba

\begin{abstract}
Research in family medicine contributes to the increase of knowledge, and its practical application improves the work of family physicians. Although research in family medicine in the Republic of Croatia has a long tradition, no sustainable research network exists as yet. Enhancing such a network is essential to efficaciously conduct research that is specific and important for family practice. This article describes the experiences of other countries and offers a proposal for a conceptual model for the development of a permanent research network in family medicine through three key elements: recognition of research as an indicator of quality of care that is specifically funded, introducing a continuing cycle of education for family physicians/researchers in the field of scientific research and building the capacity of academic family medicine and the success of their applications for domestic and international projects and funding sources. Conclusion. The application of the conceptual model from Australian primary health care research, adjusted to our circumstances, could further enhance research capacity building in Croatian family medicine.
\end{abstract}

Key words: Research capacities, Family medicine.

\section{Introduction}

If you keep on doing what you've always done, you'll keep on getting what you've always got.

W.L. Bateman

In countries with well-developed family medicine, patients have better health outcomes and health systems cost less than in countries where family medicine is poorly developed (1). Quality health care for the population at the primary level reduces waiting time, the unnecessary and excessive use of diagnostic tests ("hyper-diagnostics"), and possible inappropriate treatment, and is one of the most powerful means of advancing health care $(2,3)$. The General Practitioner's (GP's) office is the first place of contact between patients and the health care system, where about $90 \%$ of all contacts between doctors and patients take place (4), and most health problems are solved. Scientific research in family medicine practices, in real-life situations, with a variety of patients, burdened by a wide range of diseases, conditions, comorbidities and problems (in a so-called "unselected" sample of health care users), is useful for patients, doctors and the 
health system as a whole. Just such research and its results could contribute to an increase in the system's effectiveness and the improvement of the population's health $(5,6)$.

The aim of this article was to observe the current situation in the field of family medicine research in European countries, and in Croatia, and offer some enhancement proposals.

\section{Methods}

We searched the PubMed/MEDLINE database for articles using the keywords: general practice and research. The inclusion criteria were: observational studies or reviews published in the last 15 years. Out of 1453 articles, 37 met the inclusion criteria, two reviewers read them independently and 28 were included in the study. One additional reference was added for its historical importance, although it did not meet the publishing year inclusion criterion. A synthesis of the main results of studies included is presented in this overview.

\section{Results}

\section{The tradition of research in the family medicine setting}

Research in family medicine has a long historical tradition. Many family physicians in the past were excellent individual researchers, such as Edward Jenner and James Parkinson, whose discoveries changed the history of medicine (7). However, compared to other clinical specialties, family medicine is relatively young, it has only recently been recognized as an academic discipline, and it is still developing as a research discipline. At its centre is the patient, as a complete biopsychosocial being, approached holistically and provided with continuing care over time, with the focus on the family and community. The framework for research topics is shown in the detailed document: "Research Agenda for General Practice / Family Medicine and Primary Health Care in Europe," in the form of a manual for GP-researchers in family medicine and health policymakers, written by a group of experts from the organization, the European General Practice Research Network (EGPRN), of the World Organization of National Colleges, Academies and Academic Associations of General Practitioners/Family Physicians (WONCA) for Europe (8). The Agenda complements the European Academy of Teachers in General Practice/Family Medicine (EURACT) Educational Teaching Agenda, which addresses academic and vocational training (9).

\section{Research in family medicine in Croatia}

The Republic of Croatia was the first country in the world to introduce specialization in family medicine, in 1960. Currently there are four departments of family medicine at four Medical schools in Zagreb, Rijeka, Osijek and Split. The Department of Family Medicine at the School of Medicine in Zagreb was the first among them, established in 1980 and has a long tradition of quality education, research, and domestic as well as, more recently, international research projects. In 1996, the Department of Family Medicine of the Medical School, University of Zagreb and the Croatian Association of Family Medicine established the Family Medicine Research Club, which represented this network formally. It was also a valuable effort to motivate family physicians/practitioners to undertake research, relying on the academic family medicine department $(10,11)$.

After the reform of the curriculum of the Faculty of Medicine, which was adopted in 2010, the new reformed curriculum became a reality in the Republic of Croatia, starting from the academic year 2010/11. The Department of Family Medicine at the University of Split, School of Medicine saw the 
new curriculum as a chance to improve and modernize its own organization and work. The new innovative approach included two aims: to improve patient-student communication through writing letters to patients, and to introduce an evidence-based medicine (EBM) concept, not only to the curriculum, but also to family medicine practice (12-15). The Department also founded its own Journal Club for GPs to critically read papers and to encourage and help less-experienced GPs to develop research questions and conduct their own studies.

But despite all those activities, a permanent and stable network of $\mathrm{GP} /$ researchers has not yet been created. There is still no optimum "critical mass" of GPs, who would be able to conduct systematic quality studies in the field. The "culture of research" as an integral part of the daily work of family physicians has never become a reality, except for some enthusiastic individuals within family medicine departments. There has always been a gap between the "family physicians/researchers" and "family physicians/practitioners" and we can only seldom speak of family physicians' research practices, where research and practice are permanently intertwined, as for example in the Netherlands, Great Britain and Australia $(3,6,16-18)$. An average family physician in Croatia does not experience research as an integral part of their clinical work, more often it is perceived as "extra work reserved for colleagues, who want to thrive academically and to participate in science" (19).

Some research into issues important for GPs, such as primary care management, person-centred care, specific problem solving, the holistic approach and community orientation, has been conducted in the Croatian family medicine setting, doctoral theses on those topics have been written and papers published. However, overall, GPs are (with the exception of rare individuals) seldom independent researchers and are much more often the passive recipients of complete in- formation and the results of research carried out "by others, elsewhere". Unfortunately, these are mostly clinical studies conducted in secondary care, in which the influence of pharmaceutical companies and other funding agencies (either through visible sponsorships or those that are "invisible" at first sight) is often worrying. Despite the great research potential of family medicine, GPs themselves seldom manage to create and conduct high quality research, focused at the peak of the hierarchical pyramid of studies and based on the strength of evidence provided.

The number of studies, in which family medicine specialists were the principal investigators and which were conducted fully precisely in GP practices, from recruiting participants to collecting data, is praiseworthy, but still too small (20). In contrast, trials in family medicine done by "someone else", from "outside", usually with a project manager or principal investigator from a field of clinical medicine, are not so rare, and family physicians usually play a minor role in the process. It is highly questionable whether the results of clinical trials done elsewhere, with a selected sample of patients can be unconditionally and directly applied to the current population in GP care. Additional training, especially in searching and finding the best "trustworthy" evidence, as well as in critical reading and evaluation of the published results, is of crucial importance for the provision of quality care in GP offices (21-23).

\section{Teaching research in the Croatian Medical School system}

In recent years at Croatian medical schools, students have been systematically taught about the importance of evidence-based medicine and the basics of scientific research, in a variety of undergraduate courses. At the Department of Research in Biomedicine and Health, of the University of Split, School of Medicine, an integrated manda- 
tory course in research methodology and evidence-based medicine (EBM) has been introduced very early on in the curriculum and spread in smaller courses throughout 6 curriculum years (24). The Department of Family Medicine of the University of Split, School of Medicine also teaches EBM in the sixth year of the undergraduate curriculum. The latter was founded on the fact that the School of Medicine in Split nourishes an active Croatian branch of the Italian Cochrane Centre, and some teachers in the family medicine department are active members of the branch (13). Scientific research in family medicine has also been incorporated into the curriculum for the family medicine specialization course, as part of its postgraduate studies. In fact, creating an individual research plan, conducting a small research project and writing it up as a postgraduate thesis are set as an obligatory condition for GP graduation (10). All undergraduate and postgraduate forms of training are aimed at conveying to undergraduate and postgraduate students the basic knowledge and skills needed for research, and motivating them for continuous research activities later as integral part of their practice. However, a significant number of physicians employed in Croatian family medicine nowadays are middle-aged or older and did not have the opportunity to attend such an undergraduate program or postgraduate program either. Among those who did, only a minority has the motivation to initiate research and/ or participate in it. What are the reasons for this? The growing demands of various health care organizations for administrative work have become a time-consuming burden for family physicians, not leaving them enough space for medical work, prevention, and particularly, for research. In such a busy schedule in the GP's office, curative work and compulsory administration inevitably take priority over the GP's prevention and research activities: they are regularly "sacrificed" or "left for better times" (25).

A protected time, as a part of the working day, intended for research activities, exists in many countries of the world (26), but not in Croatia. Health policies in our country have never recognized research as an important element in improving the quality of the work of GPs and have not validated it in any way. Even GPs, who are trained for research and who have an intrinsic drive for it, alongside the lack of time mentioned, are also faced with an additional obstacle when trying to answer questions arising from their practice: the inability to search their own database with ease! Namely, the electronic health records (e-records), compulsory in the fully computerized family medicine system in Croatia, are not standardized, and have very poor usability for research purposes (27). Therefore, their standardization at state level is a priority and a fundamental prerequisite for the future development and enhancement of the capacities of family medicine research, especially because the systematic investigation of their own daily work through the information accessible in the e-records, is usually the first crucial step in planning a GP's future research.

For all of these reasons there have not been enough quality studies undertaken so far in family medicine in Croatia, they are not systematized, and only a small number of creative enthusiasts have tried to implement them (mostly permanent members of Departments of Family Medicine, or their associates).

\section{Experience from other countries}

Many countries with well-developed family medicine have elaborated systems and established practices in research, with their own research capacities in family medicine, and, as study groups, systematically publish the results of their research in international 
journals. Their studies are normally based on the existence, constant maintenance and strengthening of organized networks of researchers working together.

What makes those countries different from us and why are they more successful in research? In this overview, we chose the examples of the UK, the Netherlands and Australia, which are traditionally used as role models for other countries, both in the development of general practice and research networking. In the UK, the National Health Service (NHS) and the Ministry of Health fund research development and allocate substantial funds to research networks in primary health care ( $\mathrm{PHC})$. A prototype of such a functioning network is The West London Research Network (WeLReN), covering 979 GPs, with about two million people in their care (6). The Royal College of General Practice (RCGP) involves family physicians/practitioners through the Research Ready Program in research and projects, which are additionally financed (18). In Norway, by participating in research, practices obtain points for re-licensing, which is required every five years (16).

In the Netherlands, the networks of researchers (the best known is in Nijmegen) traditionally "rely" on academic departments and departments of family medicine at medical schools, as centres of excellence, that provide continuous education, mentoring and support (3). The Australian government, from 2000 to 2004, supported the strategy to develop research networks in primary health care (the Primary Care Research, Evaluation and Development Strategy, PHC-RED) with \$A 50 million. From 2000 to 2005, every department of family medicine at Australian universities received \$A 200,000 a year to build their research capacities, according to their own strategic plans (17). So the financial support that Flinders University in South Australia received through the PHCRED program (bursaries, writing grants and research fellowship) resulted in the strengthening of research skills, confidence, outcomes and family physicians' interest in research (28).

Strengthening research capacity is one of the most powerful and cost-effective ways of improving the health of the community. Therefore, the governments and health politicians of these countries recognized the importance of creating quality research capacities in family medicine, and have allocated and still allocate significant funds for that purpose. Designing and planning and / or GP participation in research is evaluated as one of the criteria for quality of care, and it is specifically funded. Each year GP practices are assessed and characterized as "research practices".

\section{Challenges in building family medicine research capacities - the Australian model}

The conceptual model of research capacity building in primary health care $(2,29)$ is also applicable to the situation in Croatia. According to this model, there are four different groups of GPs:

1. Physicians who do not participate in research (nonparticipants),

2. Physicians who participate to some extent (participants),

3. Physicians who manage their own research and educate others (managing/training),

4. The academic segment of family medicine that conducts research aimed at gaining a doctor of science degree and the scientific advancement of its members, prepares applications for research projects and funds, initiates studies, publishes results in journals, and teaches students and academics.

In order to create research capacities in family medicine, the awareness must be raised of the first group of the importance of research for improving their work, their motivation strengthened, and their basic knowledge and needed skills increased. The 
second group, already included in research, should improve their research skills and be encouraged to set their own hypotheses, and design, develop and ultimately implement the research results. The third group, which has already conducted research, should be given further training in new techniques and methods and encouraged to find funding for research through projects (instead of selffinancing, which is often rather overpriced and unacceptable over a long period). Finally, academic family medicine as a centre of excellence and a "learning organization" has a key role in the oversight, support and encouragement of less experienced researchers from all three groups, as well as providing on-going mentoring support (Figure 1).

Eventually, the gradual shift of some of the researchers from "left to right" might occur (Figure 2), i.e., from the first to the second group, from the second to the third and

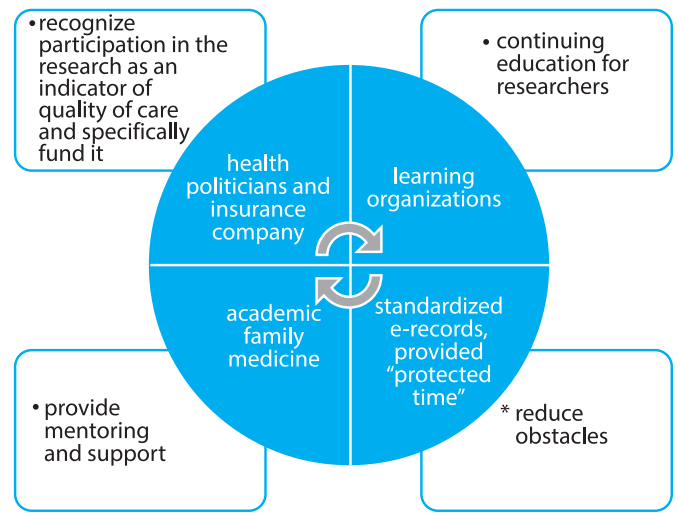

Figure $1 \mathrm{~A}$ conceptual model of creating a network of researchers in family medicine applied to Croatia.

from the third to the fourth group. Research capacity building in family medicine is not an easy process. In Croatia it is further aggravated by the lack of funding for the creation of a national network of researchers in family medicine. There are numerous obsta-

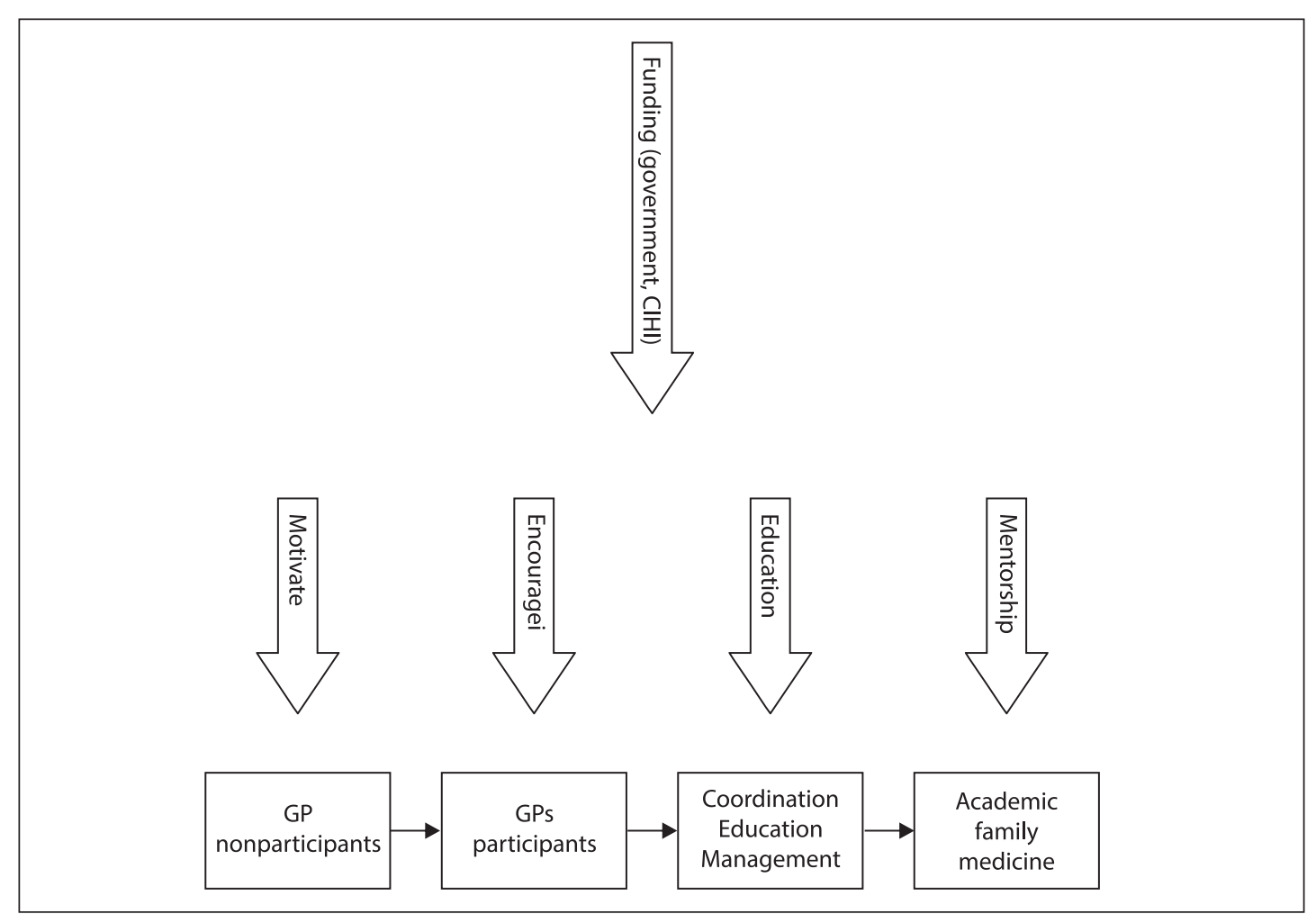

Figure 2 Four groups of researchers in family medicine and their flow through the process of education and additional education (lifelong learning). GPs - family physicians, CIHI - Croatian Institute for Health Insurance. 
Table 1 Summary of obstacles to research in Croatian GP offices

\begin{tabular}{|c|c|}
\hline Type of obstacles & Content \\
\hline From the system & $\begin{array}{l}\text { - There is no allocation of funding for the development and maintenance of research networks. } \\
\text { - The insurance company (CIHI) does not include research in GP practices among its "quality of } \\
\text { care" indicators nor does it specifically fund them. } \\
\text { - Researchers have no "protected time" for research during working hours in the office. } \\
\text { - If they want to investigate, they must do it in their own time and at their own expense. }\end{array}$ \\
\hline From physicians & $\begin{array}{l}\text { - Lack of time for research due to the excessive number of daily visits (free and uncritical } \\
\text { "access" to the PHC system). } \\
\text { - Often wrong attitudes towards research and EBM. } \\
\text { - Lack of education, knowledge, skills and competencies for research. } \\
\text { - Dedicated to earning money, do not recognize and appreciate the value of research. }\end{array}$ \\
\hline $\begin{array}{l}\text { From academic family } \\
\text { medicine }\end{array}$ & $\begin{array}{l}\text { - There are few qualified and experienced scientists/mentors. } \\
\text { - Lack of skills in writing applications for research projects. } \\
\text { - Low efficiency in getting national and international projects funded. } \\
\text { - Overloaded by regular teaching. } \\
\text { - In science as in healthcare, clinical and basic research have advantage over "applied" science, } \\
\text { not being recognized even in medical schools. }\end{array}$ \\
\hline
\end{tabular}

cles to establishing a network of researchers in Croatia (Table 1).

Although research in $\mathrm{PHC}$, including family medicine, has a relatively long historical tradition in Croatia, it does not exist as a continuous and permanent "current" activity based on a stable network of researchers. The small academic community in Croatian family medicine works persistently to support giving research a worthy place in the organization and funding of family medicine. A rather small number of teaching practices has been recognized (though not paid, but at least GPs can formally have fewer patients, $80 \%$ of the average list, to be able to teach). The process of research in family medicine should be systematic and planned long-term, permanently financed and encouraged, and not occasional or in spurts. Several preconditions should be met in order to create a network of researchers that would undoubtedly strengthen research in family medicine:

- Health policies and the system overall need to recognize the creation of research and/or participation in it as a valid and veri- fiable indicator of quality of care, which is specifically funded, and thereby provide "protected time" for research.

- Continuous education courses for GP/ researchers (potential and existing ones) should be introduced, through basic and advanced workshops and courses in the field of scientific research.

- The number of qualified scientists and mentors should be increased in order to strengthen the capacities of academic family medicine and increase application performance, for both domestic and international projects and funds, which the upcoming accession of Croatia to the European Union makes highly topical.

Such a model could create, continuously maintain and strengthen the network of researchers in family medicine in Croatia, which undoubtedly have great research potential but it has so far been underused.

Research in the family medicine setting could have many advantages. Studies conducted in family medicine practice could perhaps represent "real clinical practice" and reflect everyday practice better than 
artificial clinical studies. Also recruiting a large sample of patients (especially those with comorbidities) can be much easier in primary health care.

The Australian model includes motivating, recruiting and training GPs to become part of the permanent research network, and health policies there recognize the importance of research in family medicine as a basis for everyday quality care provision. Although this model demands constant funding through health policies, it significantly improves the clinical excellence important for patients in GP care.

\section{Conclusion}

Research is a critical element in the further development and improvement of the quality of all branches of medicine, including family medicine. On the basis of the results and experiences of other countries, we propose the application of the Australian model for further enhancement of research capacities in Croatia.

Authors' contributions: Conception and design: DV; Acquisition, analysis and interpretation of data: DV; Drafting the article: DV; Revising it critically for important intellectual content: DP.

Conflict of interest: The authors declare that they have no conflict of interest.

\section{References}

1. Starfield B, Shi L, Macinko J. Contribution of primary care to health systems and health. Milbank Q. 2005;83:457-502.

2. White F. Capacity-building for health research in developing countries: a manager's approach. Rev Panam Salud Publica. 2002;12:165-72.

3. van Weel C, Rosser WW. Improving health care globally. A critical review of the necessity of family medicine research and recommendations to build research capacity. Ann Fam Med. 2004;2(Suppl 2):S5-16.

4. Anonymous. The European definition of general practice/family medicine. Barcelona: WONCA Europe; 2002. p. 4-43.
5. van Weel C. General practice research networks: gateway to primary care evidence. MJA. 2002;177:62-3.

6. Thomas P, While A. Increasing research capacity and changing the culture of primary care towards reflective inquiring practice: the experience of the West London research Network (WeLReN). J Interprof Care. 2001;15:133-9.

7. Cope Z. Some famous general practitioners and other medical historical essays. 1st ed. London: Pitman; 1961.

8. Hummers-Pradier E, Beyer M, Chevallier P, EilatTsanani S, Lionis C, Peremans L, et al. Research Agenda for General Practice/ Family Medicine and Primary Health Care in Europe. Maastricht: European General Practice Research Network EGPRN; 2009. p. 3-68.

9. Heyrman J, ed. EURACT Educational Agenda. Leuven: European Academy of Teachers in General Practice EURACT; 2005.

10. Vrcić Keglević M, Katić M, Tiljak H, Lazić Đ, Cerovečki Nekić V, Petriček G, et al. Specialization in family medicine-has all the planned been achieved? [In Croatian] Acta Med Croatica. 2007;61(1):95-100.

11. Jakšić Ž. Overwiews on development of family medicine/general practice [In Croatian]. Zagreb: Škola narodnog zdravlja "Andrija Štampar" i Hrvatska udružba obiteljske medicine; 2001.

12. Grković I, Sapunar D, Marušić M. Ways to adress challenges of a modern medical curriculum: Living academic medicine at the University of Split, School of Medicine. Acta Med Acad. 2012;41(1):7-17.

13. Pavličević I. The new curriculum for family medicine at the University of Split, School of Medicine. Acta Med Acad. 2012;41(1):26-37.

14. Mrduljaš Đujić N, Pavličević I, Marušić A, Marušić M. Students' letters to the patients as a part of education in family medicine. Acta Med Acad. 2012;41(1):52-8.

15. Vrdoljak D. Teaching evidence based medicine in family medicine. Acta Med Acad. 2012;41(1):88-92.

16. Ried K, Farmer EA, Weston K. Setting directions for capacity building in primary health care: a survey of a research network. BMC Fam Pract [serial on the Internet]. 2006 [cited 2013 January 23];7:8. Available from: http://www.biomedcentral.com/1471-2296/7/8.

17. Del Mar C, Askew D. Building family/general practice research capacity. Ann Fam Med. 2004;2(Suppl 2):S35-40.

18. Campbell SM, Roland MO, Bentley E, Dowell J, Hassal K, Pooley JE, et al. Research capacity in UK primary care. Br J Gen Pract. 1999;49: 967-70. 
19. Novak K, Mirić D, Jurin A, Vukojević K, Aljinović J, Čarić A, et al. Awareness and use of evidencebased medicine databases and Cochrane library among physicians in Croatia. Croat Med J. 2010;51:157-64.

20. Katić M, Budak A, Vrcić-Keglević M, BlažekovićMilaković S, Bergman Marković B, Tiljak H, et al. Scientific and research projects of the department of family medicine-contribution to the identity of general practice as scientific discipline[In Croatian]. Liječ Vjesn. 2002;124(Suppl 2):S32-6.

21. Kekki P. Promoting clinical research in general practice. Educ Health (Abingdon). 2005;18:283-9.

22. Wandersman A, Duffy J, Flashpohler P, Noonan $\mathrm{R}$, Lubell K, Stillman L, et al. Bridging the gap between prevention research and practice: the interactive systems framework for dissemination and implementation. Am J Community Psychol. 2008;41:171-81.

23. Mc Kenna H, Ashton S, Keeney S. Barriers to evidence based medicine in primary care: a review of the literature. Int J Nurs Stud. 2004;41:369-78.

24. Marušić A, Sambunjak D, Jerončić A, Malički M, Marušić $M$. No health research without education for research - experience from an integrated course in undergraduate medical curriculum. Meda Teach 2013 BMJ. 2013 [Epub ahead of print].
25. Brotons C, Bjorkelund C, Bulc M, Ciurana R, Godycki-Cwirko M, Jurgova E, et al. Prevention and health promotion in clinical practice: the views of general practitioners in Europe. Prev Med. 2005;41:595-601.

26. Farmer E. A conceptual model for capacity building in Australian primary health care research. Aust Fam Physician. 2002;31:1139-42.

27. Katić M, Soldo D, Ozvačić Z, Blažeković-Milaković S, Vrcić-Keglević M, Bergman-Marković B, et al. Information systems and the electronic health record in primary health care. Inform Prim Care. 2007;15(3):187-92.

28. Ried K, Montgomery BD, Stocked NP, Farmer EA. General practice research training: impact of the Australian Registrar Research Workshop on research, skills, confidence, interest and involvement of participants, 2002-2006. Fam Pract. 2008;25:119-26.

29. Ried K, Farmer EA, Weston K. Bursaries, writing grants and fellowships: a strategy to develop research capacity in primary health care. BMC Fam Pract [serial on the Internet]. 2007 [cited 2013 February 26];8:19. Available from: http://www. biomedcentral.com/1471-2296/8/19. 